\title{
Einsame Spitze? \\ Warum berufstätige Frauen glücklicher sind
}

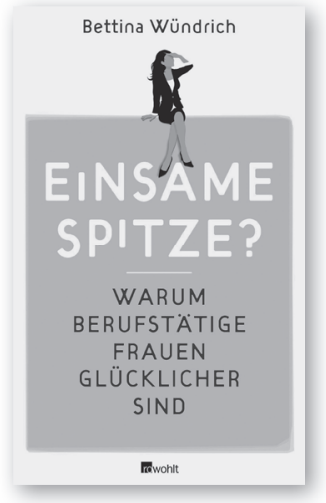

Bettina Wündrich

„Einsame Spitze? Warum berufstätige

Frauen glücklicher sind“

Rowohlt Verlag, Hamburg 2011

ISBN 978-3-498-07380-0

Gebunden, 223 Seiten, 16,95 Euro

Auslöser für dieses Buch war ein

Klassentreffen. Bettina Wündrich

hat lange für Frauenzeitschriften gearbeitet, war u. a. stellvertretende Chefredakteurin bei „Elle“ und ist Gründerin der Zeitschrift „emotion“. Bei einem Abiturstreffen fühlt sie sich in Anwesenheit ihrer ehemaligen Klassenkameradinnen dennoch unwohl in ihrer Designerkleidung, sie sieht ihren Lebensentwurf auf dem Prüfstand. Sie ist kinderlos und Single - „ein Prinzenrolle-Keks ohne Schoko“. Die Atmosphäre scheint von Konkurrenzdenken vergiftet zu sein, wobei sich die erfolgreiche Journalistin plötzlich auf der Verliererseite sieht, weil sie Trümpfe „Meine Kinder! Mein Mann! Mein Hund! “ nicht vorweisen kann. Nach dem ersten Schock erkennt sie aber, dass hinter der Protzerei eine große Unsicherheit steckt und fragt sich, warum Frauen heute, wo ihnen vermeintlich alles offensteht, nicht glücklich sind.

Bettina Wündrich hat sich also eine Auszeit genommen, um intensive Gespräche mit berufstätigen und nicht berufstätigen, mit erfolgreichen und (manchmal auch nur gefühlt) gescheiterten Frauen zu führen. Sie selbst hat Soziologie studiert, jedoch betont sie, sie habe diese Entscheidung nur aufgrund einer schlechten Berufsberatung getroffen. Ihr Traum war es immer, Journalistin zu werden. In diesem Beruf arbeitet sie leidenschaftlich gern und trennt daher nicht streng zwischen Karriere und Privatleben. Als Redakteurin hat sie sich immer schon damit beschäftigt, was Frauen glücklich macht. Ihr Buch ist aber keine Wohlfühlliteratur und reiht sich auch nicht ein in die lange Liste von Appellen, was Frauen „sollen“, um glücklich zu sein. In lockerer Sprache analysiert Bettina Wündrich die bestehenden Strukturen, zuweilen mit einem Hauch Selbstironie.

Bettina Wündrich stellt fest, die „gläserne Decke“ sei heute aus Beton, die Frauenquote ist für sie also eine Notwendigkeit. Für sie ist klar, dass sich der Feminismus nicht erledigt hat. Ihr Hauptanliegen besteht jedoch nicht darin, ein knallhartes feministisches Programm zu schreiben. Ihr geht es um eine realistische Sicht auf die Dinge, um Miteinander statt Gegeneinander. Auch wenn das Buch keine Anleitung sein soll, ist „Einsame Spitze? “ den Nichten der Autorin gewidmet. Bettina Wündrich will zu einem selbstbestimmten Leben ermuntern. Die Leser/innen/schaft möchte sie vor allem informieren. Bettina Wündrich rät, rechtzeitig Prioritäten zu setzen. Für ein selbstbestimmtes Leben sei finanzielle Unabhängigkeit essentiell. Dr. Angelika Dammann, seit Juli 2010 Personalchefin und damit erste Frau im Vorstand von SAP zitiert sie so: „Es gibt kein „Jein“ zur Karriere als TopFührungskraft." Es stimmt nachdenklich, dass eben diese Spitzenfrau im Juli 2011 von ihrem Posten zurückgetreten ist, weil das Unternehmen nicht mehr zu ihren - vertraglich abgesicherten - Heimflügen stehen wollte. Neben einem uneingeschränkten Ja zur Karriere sei gezieltes Netzwerken ein wichtiger Faktor für Erfolgsfrauen.

Bettina Wündrich fordert, die Chance einer Ausbildung zu nutzen, wobei ihr klar ist, dass sie sich damit an die privilegierte Mittelschicht wendet. Die Emanzipation habe Frauen viele Möglichkeiten eröffnet. Sie stellt dabei heraus, der gesellschaftliche Wandel beträfe Männer und Frauen gleichermaßen. Auch wenn der Untertitel ihres Buches missverständlich erscheinen mag: Die Autorin predigt nicht etwa Karriere statt Familie. Vielmehr sollten Frauen mit verschiedenen Lebensmodellen gemeinsam an einem Strang ziehen. Sie will dazu ermutigen, sich von Klischees und damit von übertriebenem Perfektionismus freizumachen.

Sie beantwortet schließlich auch die Frage nach dem Glück: „Eigene Ideen, persönliche Ziele zu verfolgen, das ist es, was uns glücklich macht“. Bettina Wündrich ist überzeugt, dass Frauen Karriere machen und sich auch an der Macht beteiligen wollen - nur eben zu ihren Bedingungen. Weil sich Frauen mit ihrem Beruf stark identifizieren, wollten sie etwas finden, wo sie sich voll einbringen können und wertgeschätzt werden. Sie fordert daher für das Arbeitsmodell der Zukunft mehr Flexibilität, eine andere - für beide Geschlechter letztlich gesündere - Arbeitskultur, ein Karrieremodell, das Familie integriert. Gerade jetzt sei der richtige Zeitpunkt, diese Forderungen zu stellen, da die Wirtschaft das Potenzial von Frauen entdecke.

„Einsame Spitze?“ ist ein kluges Plädoyer für gegenseitiges Verständnis, Gelassenheit und Flexibilität - vor allem im Denken. Knapp in der Darstellung ist das Buch gut recherchiert und bekommt durch Ausschnitte aus persönlichen Gesprächen besondere Glaubwürdigkeit. Das frische Cover passt zu dem Buch, weil es kein altkluger Ratgeber ist. Jedoch hätte man sich etwas Entschiedeneres gewünscht: Schließlich ist der Stil der Autorin zwar versöhnlich, die Thesen aber mutig ohne zu bevormunden, sie machen Mut. „Einsame Spitze?“ gehört in jeden gut sortierten Bücherschrank. Ohne Scheu und dafür mit einem Augenzwinkern erinnert das Buch uns: „Da wo die Angst sitzt, geht der Weg lang“. (Katharina König, Beisitzerin im Bundesvorstand als Vertreterin der Mitglieder in Ausbildung; Wiss. Mitarbeiterin, Freiburg i. Br.) 